\title{
Human Potential in the System of Sustainable Development
}

\author{
Tatyana Snegireva, ${ }^{1, *}$, Gennady Kayachev ${ }^{2}$, Albert Falaleev ${ }^{2}$, and Sergey Kurgansky ${ }^{3}$ \\ ${ }^{1}$ Russian State Library, International Education Cooperation Sector, 119019 Vozdvizhenka st., 3/5, \\ Moscow, Russia \\ ${ }^{2}$ Siberian Federal University, 660075 Lida Prushinskaya St. 2, Krasnoyarsk, Russia \\ ${ }^{3}$ Irkutsk National Research Technical University, 83, Lermontov street, 664074 Irkutsk, Russia
}

\begin{abstract}
The essence of sustainable development is that the progress of the current generation does not go against the interests of future generations. In the classical definition, the balance between generations is understood as the balance of needs. However, the word "needs" can be interpreted differently. First, we can talk about the ability to meet the needs in the context of the availability of natural resources. This means that we must leave to future generations the same amount of resources that we have, so that they can meet their needs with these resources. Secondly, we can talk about the ability to meet the needs as a standard of living. This means that for future generations it should be at least the same as the standard of living of our generation. At the same time, it is absolutely not necessary that this be achieved due to the availability of natural resources. For example, we can now invest some resources in the development of human capital and knowledge, and future generations will provide a higher standard of living through the growth of knowledge. Consequently, the factor of human capital, determining the pace of introduction of innovative technologies and moving away from resource-intensive industries, will determine sustainable development in the process of transition to a post-industrial economy.
\end{abstract}

\section{Introduction}

The founders of the concept of sustainable development drew attention to the fact that human activity has already gone beyond the balanced functioning of the Earth's ecosystem. The special importance of the problem of sustainable development is intrinsic to the mining sector of national economy which nowadays is a main source of the environment pollution [1-5]

The conclusion about reaching the limits of growth was based on a number of estimates. Thus, despite successful economic growth in some regions, since 1974, the decline in world production per capita began. At this turn the peak of the growth of living standards in the world (average per capita) was reached. From the mid-twentieth century, a fifth of arable land has been withdrawn from agricultural use, and recently every year 8.5 million hectares of the most productive regions of the planet go out of use. Improving the efficiency of the

Corresponding author: snegireva_tv@mail.ru 
global agro-industrial complex no longer compensates for the absolute reduction of its resource base. Between the 1950s and the 1990s, the population doubled and the global economy grew almost 5 times, as a result of which the equilibrium in nature was disturbed and the preceding growth trends occurred. World economic growth reached a historic peak of $5.2 \%$ in the $60 \mathrm{~s}$, slowed to $3.4 \%$ in the $70 \mathrm{~s}$ and $2.9 \%$ in the $1980 \mathrm{~s}$. In the $1990 \mathrm{~s}$, the growth rate of the global economy was about $0.5 \%$ per year, and per capita living standards continued to decline [6].

Thus, according to the estimates of the concept of sustainable development authors, the critical threshold for the sustainability of society has already been surpassed, since humankind consumes significantly more resources than the laws of stable functioning of ecosystems allow. Confirming the conclusion about the achievement of the planetary limits of economic growth and the state of "zero growth" (and even "dumping" of capacities in a number of regions), some authors drew attention to the factor of underdevelopment of traditional societies [7]. He assesses poverty as a major global problem, since it is both the cause and effect of excessive demographic growth.

The specified attention of the concept of sustainable development paid to the underdeveloped countries highlights the main contradiction of the global system as the contradiction between the North and the South. This contradiction is associated with more intensive use of human capital by the technologically advanced countries of the North, and with underdeveloped human potential in the resource-producing countries of the South.

The principle of maximizing the use of human potential as the basis for sustainable development was taken up by European Social Democracy, in particular the "Independent Commission on International Development Issues" by German Chancellor W. Brandt. In the 1980s, the Independent Commission on Disarmament and Security and the International Commission on Environment and Development were formed under the chairmanship of the leaders of the Social Democratic parties and the Prime Ministers of the Scandinavian governments. The result of their work were various memorandums, declaring the increasing importance of civil society, innovative and entrepreneurial initiatives in the modernization of the economy and society in accordance with modern environmental standards.

\section{Materials and Methods}

The Sustainable Development Strategy, approved by the UN General Assembly [8], provides for:

- meeting the needs of modern generations without threatening the ability of future generations to meet their own needs;

- respect for available global resources and environmental potential;

- early prevention of environmental problems as the most effective and economical means of achieving environmentally sound development;

- the major objectives of the environment and development policy should include the preservation of peace, the revitalization of economic growth and the alteration of its quality, the solution of the problem of poverty, the satisfaction of the immediate needs of people, the demographic problem, the preservation and strengthening of the natural resource base, the reorientation of technology and an integrated approach to environmental and economic issues in the decision-making process;

- equitable distribution of environmental protection costs, equitable distribution of economic development benefits between and within countries, as well as between current and future generations.

As has been repeatedly noted recently, the decisions of the UN Conference in Rio de Janeiro are practically not being implemented. These decisions were previously rated as unrealistic, although they were significant enough to mobilize public opinion. Thus, for 
example, G. Daily, an economist at the World Bank's Environmental Protection Department, said regarding "Agenda 21": "This discouraging document is nothing more than the joint snoring of idle economists in the deepest dogmatic slumber." [9]

At the same time, the discourse on discussing the problem of sustainable development is well-established. Consequently, discussions around sustainable development can be viewed as a subjective reflection of a latent, ill-understood, objective mental form. Consequently, explication is not a concept of sustainable development, but the underlying objective mental form and an analysis of strategies that are permissible within this form.

Evaluating the structure of the implicit objective mental form of the concept of sustainable development, let us fix its main aspects, on the basis of which the configuration of the use of human potential arises in a post-industrial environment-oriented economy.

The first cornerstone is "generation centrism". Of all the definitions of the concept of sustainable development, the most frequently used definition of the Brundtland Commission is: "Sustainable development is development that meets the needs of the present generation and does not jeopardize the ability of future generations to meet their own needs" [10]. The balance of intergenerational and intragenerational interests plays an important role in the concept of sustainable development. Intergenerational equilibrium is understood as an equitable distribution of resources between present and future generations, and the intergenerational aspect can be understood as equality in distribution within the same country and between different countries within the same generation.

The second cornerstone is "economocentrism". Extreme underutilization of human potential poverty - is assessed as a key global problem, the solution of which is a prerequisite and condition for solving other global problems (first of all, demographic and environmental problems). The Plan of Implementation of the World Summit on Sustainable Development (Johannesburg, 2-4 September 2002) also puts poverty overcoming at the forefront: "The eradication of poverty is the greatest global challenge facing the world today and is a prerequisite for sustainable development especially developing countries." [11] Thus, the concept of sustainable development focuses on the reorganization of economic activity.

The third cornerstone is "natural centrism". Attention is paid to the protection of the environment, the preservation of ecosystems, reproducible natural resources and biodiversity, the balance of demographic growth and biospheric restrictions.

On the basis of the three "whales" of the concept of sustainable development, an image of sustainable development economy emerges, which, firstly, uses natural resources rationally and, secondly, optimizes the intergenerational transmission of natural resources.

The question arises: in the framework of which economic system (model) is a possible economy of sustainable development? "Agenda 21 " is permeated with the pathos of an effective market. At the same time, the very fact of adopting such a concept, as well as many reservations regarding the use of market instruments, testify, in our opinion, about the "failure of the market". Taking into account that "Agenda 21" contains a steady turnover of "economic and market", we can assume that sustainable development economics is not identical to a market economy, although it uses its tools. Therefore, a sustainable development economy can exist and develop in a non-market format.

In general, the economic life of a society includes a limited set of mutually complementary spheres of economic life, namely:

- team economy - the market economy;

- life supporting economy - the military economy,

- moral economy - the traditional economy,

- prestigious economy - the shadow economy.

Each of the spheres of economic life is characterized by a specific form of production and exchange, in particular: the market economy - commodity exchange, the moral economy "help exchange", the prestigious economy - gift exchange, the traditional economy - service 
exchange, etc.

The focus of economic science is still the market economy due to the high uncertainty in the behavior of its agents. Recently, economists have begun to more actively study the institutions of the command economy (especially in the political economy of socialism) and the shadow economy. The economic anthropology (economic ethnology), the life-supporting economy, the prestigious economy, and the moral economy are examined. On the periphery of economic thought are the military economy and the traditional economy (studied mainly by historians).

Thus, when deciding on the systemic identity of a sustainable development economy, one has to make a choice from a limited set of ways to organize economic activity. By a combination of two criteria: the rational use of natural resources and the use of human potential in the translation of natural resources - the economy of sustainable development, should be attributed to the system of traditional economics.

\section{Results and Discussion}

The starting point for a precise exit of the Russian economy from the structural crisis should be the understanding that the initiation of new industrialization will lead to the need to develop a multilateral mechanism for involving human capital in it. However, the current methodology for studying structural changes in the economy is technocratic, and the postulates and theoretical conclusions based on research models of liberal methodology have failed to resolve the growing contradictions in the field of structural and technological renewal and reproduction of highly intelligent, productive, renewable driving forces for sustainable socio-economic development because the externalities for engaging human capital are: creation and distribution the use of new products and technologies, the rapid development of new technologies, their introduction into production and life, the ability for more complex and productive work, the generation of innovations, etc.

The content, structure and forms of labor and human capital, its capitalization are changing dramatically. A person's creative abilities, his creative competences expand the boundaries of production possibilities, from the production factor, human capital, namely, the use of human abilities, becomes the dominant of economic relations, and their development and growth in the ultimate goal of the functioning of the national economic and social subsystems. Under these conditions, there is an increasing demand for the concept of institutionalizing the involvement and integration of various forms of human capital based on the principle of social structuralism, permeating the entire structure of economic relations in the process of unfolding the new industrialization of the Russian economy.

The key prerequisites for the implementation of the new industrialization process in sustainable development are closely related to the expanding of human capital, and can be defined as follows:

1. Creation of viable conditions for the realization of human, as an active subject of the economic system, which, in the context of the development of environmental views on the process of the functioning of the economy, consists in creating effective and nature-oriented institutions ("rules of the game").

2. The subordination of the created mechanism is primarily to the interests of the person in order to ensure the possibility for his self-sufficiency, in conditions when the nature and functioning of new technologies require the employee to transition from the state of an external regulator to the state of the organic part of modern technologies.

The main principle of defining structural approach as a methodology of sustainable development is human-centeredness or human centrism, thanks to which the analysis of a person, or rather his (her) ability to generate new knowledge, as a key factor of the modernization process, manifests the principle of the primacy of the human role in 
economical and ecological relations through the prism of dialectics (understanding as "homoeconomicus", but as the basis of the structural development of the economy in the long term). This principle is that a person is a key factor in realization of positive structural changes and, at the same time, the main goal of the policy of sustainable development, since the socialization of convergent structure-forming technologies stimulate the expansion of the recycling as the industrial breakthrough of Russian economy.

Based on the new model of sustainable development, proposed by the authors, the directions of state policy formation were formulated considering human capital involvement, as follows:

- the state should give a person the starting point for investments to human capital due to the effective institutionalization of conditions for the growth of living standards, which will serve as a motivating factor for the realization of productive resource-saving technologies in the context of sustainable development;

- development of the country's production forces based on the latest technological structures in order to maintain the ability of individuals to use goods and services with the highest utility without damage growth for environment;

- the formation of a social basis oriented towards active self-realization, therefore the members of special social groups will be assured of the correctness of the development path chosen by the state and will become the basis for sustainable development. Under the conditions of sustainable development, these groups should be formed from scientists and engineers.

- creating conditions for improved communication of government, society and goods producers, which can be an effective tool for public control on nature preservation.

It was noted that the most effective and efficient transformation of the economy will be in the case of its implementation on the basis of a sustainable development initiated "from above".

Today, the state is required to purposefully form the institutional environment, to broader involvement of economy institutions, in order to develop industries with a multiplicative impact that meet the needs of the population, in particular in environment-friendly productions.

In the conditions of up-to-date efficiency of human capital involvement in the industrial sphere, it is necessary to form institutions that promote human development, the realization of its productive and social capital through the improvement of the system of material remuneration for productive work in the conditions of sustainable development.

Improvement of the material remuneration system should be focused on the reproduction of the labor force, which presupposes maintaining and restoring a person's ability to work, improving the skills of the workforce and implementing the function of forming future suppliers of labor, as well as motivating the realization of productive capital in industrial production.

\section{Conclusion}

Thus, the concept of sustainable development revives the values of the innovative economy, which explains the attention of its authors to developing countries. In the context of the importance of global natural resource constraints, the institutions of innovative economy are relevant for a sustainable development economy, and resource-saving technologies are the main form of human wealth. 


\section{References}

1. S. Markov, J. Janočko, M. Tyulenev, Y. Litvin, E3S Web of Conferences, 105, 01021 (2019)

2. M. Tyulenev, S. Markov, E. Makridin, Y. Lesin, V. Gogolin, E3S Web Conf., 105, 02022 (2019)

3. V.V. Panov, O.S. Misnikov, Gornyi Zhurnal, 2015:7, 108-112 (2015)

4. I.A. Mironenko, S.I. Protasov, Journal of Mining and Geotechnical Engineering, 1:4, 2434 (2019). DOI: 10.26730/2618-7434-2019-1-24-34

5. O.S. Misnikov, Journal of Mining and Geotechnical Engineering, 2:5, 19-32 (2019). DOI: 10.26730/2618-7434-2019-2-19-32

6. S. Zhironkin, S. Demchenko, G. Kayachev, M. Ryzhkova, O. Zhironkina, E3S Web Conf., 41, 04011 (2018)

7. S. Zhironkin, D. Khloptsov, N. Skrylnikova, I. Petinenko, O. Zhironkina, E3S Web Conf., 41, 04010 (2018)

8. UN GA, The US Sustainable Development Strategy (United Nations General Assembly, Washington, 1990)

9. G. Daily, On the critics of “Agenda 21" (EPD WB, Washington, 2000)

10. L. Oliver, Modern Sustainability, 6:16, 103-121 (2007)

11. J.R. Milligan, South Africa Journal of Economics, 123:13, 65-79 (2004) 